\title{
Why Code-switch on WhatsApp? A Quantitative Analysis of Types and Influences of Code-switching
}

\author{
Adlin Nadhirah Mohd Roslan ${ }^{1}$, Malissa Maria Mahmud ${ }^{2}, \&$ Othman Ismail $^{3}$ \\ ${ }^{1}$ Akademi Pengajian Bahasa (APB), Universiti Teknologi Mara (UiTM), Shah Alam, Malaysia \\ ${ }^{2}$ Centre for English Language Studies (CELS), Sunway University, Malaysia \\ ${ }^{3}$ Akademi Pengajian Bahasa (APB), Universiti Teknologi Mara (UiTM), Shah Alam, Malaysia \\ Correspondence: Malissa Maria Mahmud, Centre for English Language Studies (CELS), Sunway University, \\ Malaysia. Tel: 603-7491-8622. E-mail: malissam@sunway.edu.my
}

Received: August 18, 2021

doi:10.5539/ass.v17n10p43
Accepted: August 31, $2021 \quad$ Online Published: September 19, 2021

URL: https://doi.org/10.5539/ass.v17n10p43

\begin{abstract}
This paper examines an asynchronous computer-mediated communication (CMC) between bilingual university students in Malaysia, in particular via Whatsapp by appropriating a functional approach in scrutinizing the diverse types and influences for codeswitching (CS). A quantitative methodology was employed wherein a survey was designed and administered to undergraduate students from the Universiti Teknologi MARA (UiTM). A dataset from a total of 90 respondents was collected from five faculties; Academy of Language Studies, Faculty of Law, Faculty of Communication and Media Studies and Faculty of Education. The yielded findings postulate that inter-sentential code-switching was the most used type of code-switching among the respondents and habitual expression is the main factor that influence them to code-switch.
\end{abstract}

Keywords: Code-switching, Computer-Mediated Communication (CMC), WhatsApp, Bilingualism

\section{Introduction}

\subsection{Background of the Study}

Numerous scholars have described code-switching in numerous ways. It is the most widespread and distinguished traits of bilingual demeanour (Heller \& Pfaff, 2008; Schendl \& Wright, 2011; Auer, 2020). Gumperz, a forerunner in the field, demarcated code-switching as the collocation of speech belonging to two different grammatical systems or subsystems (1982). Trudgill outlines that code switching is a technique used by bilingual speakers to alternate between languages and dialects when conversing (2000). Code-switching phenomenon is eminent in Malaysia because Malaysians are at the very least bilingual, if not multilingual (Gaudart, 2002). In addition, the implementation of National Education Policy made it compulsory for Malay and English languages to be part of the core subjects, and must be taken by all ethnic groups (Lee, 2010). As such, code-switching becomes the colourful fabric of Malaysia's sociolinguistic framework.

The oscillating practice to use more than one languages or dialects is common in the Malaysian speech styles. The multilingual Malaysians, Malay, Chinese and Indian are faced with varieties of linguistics choices when communicating with people of different ethnic groups. Nonetheless, many linguists have contended that code-switching may lead to several issues such as negative repercussions in language acquisition. Purists also believed that those who code-switch are lazy, and this may affect their language development. In a similar vein, code-switching is claimed to be commonly linked with linguistic incompetence (Dewaele \& Wei, 2014). According to Ariffin \& Hussin (2011), code-switching is considered as a hurdle when learning a new language. It is noteworthy to highlight that the emphasis of code-switching researches, thus far, are predominantly centred on the use of language change, levied by the word level manipulation between speaker and listener (Fricke et al., 2016). The speakers' articulatory demeanours among bilinguals are observed to modify the phonological facets and shift the lexical choices (Tamargo et al., 2016; Shen et al., 2020). On the contrary, there are also academicians who encourage the usage of code-switching. According to Nurul, Azu, Khairunnisa \& Tengku (2015), code-switching revolutionises and enhances the creativity in expressing feelings. Code-switching also plays an important role in achieving a successful communication as it helps to emphasize the key point in a sentence. Puteh et al (2020) concurred that the occurrence of code-switching in Malaysia is a form of strategy to 
create understanding among interactants by means of the similar discourse. They further illustrated that positive social tone can be harvested via online collaborative activities. Consequently, higher self-worth can be heightened and this is viewed positively in which language is used as a form of an intermediary in a social context.

Accoding to Holmes (1992), code-switching represents a spectacle where the speakers switch their first language to their second language. In examining the occurrence of code-switching in Malaysia, WhatsApp is the most suitable instant messaging application to be used in the study. This is because WhatsApp allows its users to convey themselves creatively in online communication. Halim, Nadri \& Mahmood (2015) pointed out that code-switching is employed typically everywhere in Malaysia since Malaysians are accustomed to the practice of Bahasa Rojak. Bahasa Rojak, which is also known as Salad Language represents phrases that utilize two languages at inter and intra sentential level (McLellan, 2012; Nil, Zurina, \& Shamala, 2012). The deliberations thus far have established that there is an abundance of researches on CS in the Malaysian setting. However, many of these studies are predisposed towards face to face rather than CMC. Principally, Malaysians may be able to speak Malay and English, but it is possible that they may not be conscious of the significance, strategies and choice of CS, especially on computer-mediated communication. Governed by the social dynamics of WhatsApp as a multi-mode digitised discourse, it would be noteworthy to draw on various motivation, strategies and linguistic features to confer facets of meaning. Therefore, the aim of the research is to examine the diverse types and influences for codeswitching which occur on WhatsApp among bilingual university students in Malaysia.

\subsection{Objectives of the Study}

The purpose of this research is to examine an asynchronous computer-mediated communication (CMC) between bilingual university students in Malaysia, in particular via Whatsapp by appropriating a functional approach in scrutinizing the diverse types and influences for codeswitching (CS).

\subsection{Research Questions}

This study was delimited to analyze the different types of CS and factors that incluence CS via WhatsApp. Thus, this study attempts to answer the following research questions:

1. What are the types of code-switching mostly used by UiTM undergraduates on Whatsapp?

2. What are the factors that influence the undergraduates to code-switch on WhatsApp?

\section{Literature Review}

\subsection{Types of Code-Switching}

Poplack (1980) and Hoffmann (2014) stated that there are three types of code-switching, namely tag-switching, inter-sentential switching as well as intra-sentential switching. Tag-switching can happen anywhere without affecting the linguistic rule of the sentence. Meanwhile inter-sentential switching occurs at sentence boundaries and intra-sentential switching occurs within clause boundaries. In another light, Blom and Gumperz (2000) also classified code-switching into two categories, namely situational code-switching and metaphorical code-switching. Situational code-switching happens due to several factors which are speaker, topic and setting. According to Suryawati (2013), in this type of code-switching, the speaker has a purpose of using situational code-switching in a conversation as it is intentional. As an example, situational code-switching occurs when an individual with a low language competency participates in a discussion with a speaker, the speaker eventually code-switches in order to make the person feels comfortable in the discussion. Meanwhile, metaphorical code-switching represents a way to encourage speech acts, namely complimenting, apologising, as well as asking for a favour (Choy, 2011). Metaphorical code-switching is different than situational code-switching since it has no specific purpose and unintentional.

\subsection{Reasons and Factors of Code-Switching in Malaysia}

Many linguists are curious about the reasons and factors of code-switching. Therefore, a lot of researches have been conducted to identify the reason and factors that influence a speaker to code-switch. According to a study conducted by Malik (1994); as cited in Choy (2011), there are 10 factors that caused code-switching, specifically lack of facility, lack of register ability, speaker's emotions, emphasis of a point, habitual expressions, semantic significance, display of identity within a group, communication with various audiences, pragmatic factors, as well as attention-grabbing. People code-switch during a conversation due to several factors. Lack of facility is one of the reasons. Bilinguals tend to code-switch when they are not able to find the words in other languages as a way to express themselves and to avoid any miscommunication. Other than that, lack of register ability also 
causes people to code-switch. Bilinguals code-switch when they are not proficient in any of the languages. Hence, they find it difficult to hold a conversation when they are not able to choose the correct words in a particular language. Some people also code-switch because they choose to speak in another language in a sentence as they prefer a different language than the actual language. Speaker's emotions also play an important role in influencing the use of code-switching. Bilinguals code-switch depending on their emotions such as sad, angry, happy. This is because other words in a different language may be simpler and easier to convey at that particular time. Code-switching also occurred because bilinguals want to emphasise a point during a conversation. Joanna (2014) pointed out that code-switching happened regularly in classrooms in Malaysia as teachers tend to code-switch between English and Malay language to make the students have a better understanding. Besides that, habitual expressions are also one of the common factors that influence a lot of people to code-switch, especially in Malaysia where there are various races. The use of code-switching can be seen in greetings, discourse particles, as well as apologies. The phrase "Sorry" that has been used a lot by Malaysians in a Malay language sentence proves that it has become a habit of Malaysians to include English words into their daily conversations (Ismail et al., 2021).

Another factor is semantic significance. Code-switching can also convey important details which lead to bilinguals expressing their emotions towards other people. This helps prevent confusion and misunderstandings in the context of relational communication. Moreover, people code-switch because they want to showcase their identity within a group. For example, deliberating on the notion of code-switching as an external imposition, speakers can strategically code-switch to regulate the aspects of identity that complement the context. According to Joanna (2014), code-switching takes place in classrooms because teachers are trying to create a warm connection with the students in order to achieve the targeted learning objectives as well as to create a positive surrounding in the classroom. Furthermore, code-switching is also used to communicate with various audiences, depending on the background of the audience, which lead to the use of different languages in a single exchange of interaction. Furthermore, pragmatic factors also cause people to code-switch. The setting of the conversation such as formality determines the selection of language. Lastly, code-switching also takes place because people want to attract the attention of others in communication. Therefore, a lot of retail companies include code-switching in advertisements as a way to communicate in a friendly manner with customers as well as to grab their attention towards the products that they are promoting. According to a research that was done by John \& Dumanig (2013), it is important to include Malaysians' favourite expressions in advertisements as it helps to grab the attention of customers and develop a good point of view towards the brand.

\subsection{Computer-mediated Communication (CMC)}

Hassan \& Hashim (2009) stated that the internet, the web and technology make it easier for people to communicate with each other around the world. CMC is a medium of communication through technology, namely email, instant messaging and video call. CMC is separated into two main categories according to its feature of synchcronicity; synchronous and asynchronous CMC. Synchronous CMC helps participants connect and interact in actual time which help the participants to receive fast responses in a conversation. According to Rasdi (2016), both sender and receiver are required to be present at the same time on synschronous CMC mediums such as chatrooms, video calls and instant messaging. Asynchronous CMC, on the contrary, differs from the aspects of receiving responses from receiver as users are not required to be present at the same time. However, asynchronous CMC provides disadvantages to people as it may cause delayed responses which can be seen in emails and social media platforms which have the same characteristics as written communication.

\subsection{The Use of WhatsApp in Malaysia}

According to Constine (2018), 1.5 billion people around the world use WhatsApp for communication purposes. Ninety seven (97\%) Malaysians chose WhatsApp than any other instant messaging applications such as Telegram and WeChat (Telenor Research, 2016). Fifty one (51\%) of WhatsApp users are from Malaysia, which are the largest WhatsApp users in the world (Newman et al., 2017). The astounding number of users is due to the user-friendly features. Most importantly, WhatsApp has made it easier for people to keep in touch with each other as it has important tools such as group chats, broadcast message, phone and video call functions. WhatsApp also does not require its users to pay in order to use the application. This reason led people to abandon the traditional Short Message Service (SMS) as it charges people for every message (Resende et al., 2019). In Malaysia, WhatsApp is used a lot in teaching and learning process by educators as well as learners. This is because it helps to spread knowledge among friends, enhances the process of acquiring new knowledge and develops evaluation skills (Barhoumi, 2015). Che Su, Che Hasniza, Hassan \& Bahtiar (2018) pointed out that utilizing WhatsApp for education helps to sharpen the students' social skills and enhance the students' as well as the teachers' creativity. Educators and students can make full use of the functions in WhatsApp such as 
creating voice notes, sending photos and videos, as well as making phone and video calls. Hence, educators are able to provide an interactive learning experience and students will be more encouraged to learn.

\section{Method}

The section describes in detail how the study was conducted, including research design and approach, the setting and respondents of the study, the method used in collecting and analysing the data, as well as the ways to measure the reliability and validity.

\subsection{Research Design and Approach}

This research examines the use of code-switching among UiTM undergraduates while communicating using WhatsApp. This research is based on a descriptive research design. A survey instrument was utilised in this study to collect the data. The questionnaire consists of questions seeking information regarding the types of code-switching and the factors that lead students to code-switch while communicating using WhatsApp. In the present study, some variables were acquired from (Noor \& Mostafa, 2017), such as gender, faculty, whereas other variables were produced by the researcher. Quantitative method approach was used in conducting this study.

\subsection{Research Setting, Sample and Sampling Technique}

Research survey was created on Google Form which was then distributed through WhatsApp. The links of the survey were distributed to students of Academy of Language Studies, faculties such as Law, Communication and Media Studies and Education. The sample of this research consists of 90 Universiti Teknologi Mara (UiTM) undergraduates of Social Sciences and Humanities from Academy of Language Studies, Faculty of Law, Faculty of Communication and Media Studies and Faculty of Education. Simple random sampling technique was used to select 90 undergraduates as a sample for study. Respondents from four faculties achieved band 3 and above for MUET and they had to pass the interview conducted by the faculties, thus marked the main reason for them to be chosen for this research. Bilinguals who code-switch are individuals who are competent in both of the languages, which are English and Malay Language.

\subsection{Research Instrument}

The instrument used in this research study included the use of a research survey. The development of the survey instrument started with an in-depth review of studies related to the research questions of this research; the types of code-switching that are mostly used by UiTM students on WhatsApp and the factors that influence them to code-switch on this messaging application, WhatsApp. From the studies gathered, the researcher produced a questionnaire with a total of 6 items related to demography profile and 39 items related to the research questions of this research. The questionnaire consists of a 45 -items survey that has been separated into three parts that collected information on demographic profile, types of code-switching and factors of it. Section A which is the demographic questions contains 6 questions. Section B contains 23 questions that are related to the five types of code-switching while Section C contains 16 questions that are related to the seven factors of code-switching. Section B through Section C in the questionnaire comprises questions that were created by the researcher by referring to other studies. The questionnaire used a 10-point Likert-type scale as it gave accurate scale value for statistical analysis purposes. Prior to the actual data collection, the survey was pilot tested before it was distributed to the research subjects in order to measure the validity and reliability. A group of 10 students from four different faculties were selected to pilot test the instrument. After the students were done with the pilot test, the questions were improvised.

\subsection{Data Collection Procedures}

A survey was conducted to collect quantitative data. The subjects consist of 90 Universiti Teknologi Mara (UiTM) students enrolled in programmes, namely English for Professional Communication, English for Intercultural Communication, Malay for Professional Communication, Arabic for Professional Communication at Academy of Language Studies. Other than that, other programmes such as Law, Public Relations, Journalism, Broadcasting at Faculty of Communication and Media Studies and Teaching English as a Second Language (TESL) at Faculty of Education. The researcher was intrigued in investigating the types of code-switching that are frequently utilised by UiTM students while communicating using WhatsApp. Thus, a research was considered relevant. A questionnaire with a total of 45 items was prepared and designed by the researcher based on other published articles. Each of the question items was retrieved from 20 journal articles. Some of the studies that have been selected and analysed to create the question items were from Nik \& Suthagar (2013) and Cresensiana (2020). 


\subsection{Data Analysis}

Upon collecting the data from the questionnaire, the types and factors of code-switching have been identified. The Likert Scales were specified with a number from 1 to 10. In Section B and C, 1 and 2 refer to 'Strongly Disagree', 3, 4 and 5 refer to 'Disagree', 6, 7 and 8 refer to 'Agree' and 9 and 10 refer to 'Strongly Agree'. For quantitative data collection, cross-tabulations between faculties and the items in research question 1 and 2 were conducted. Besides that, descriptive analysis was used between variables in order to find the mean differences and standard deviation. The data was tabulated and analysed using SPSS software version 21.0.

\subsection{Reliability and Validity}

The instrument consists of a questionnaire which has a 45 -items questionnaire that has been separated into 3 different parts that collected information on demographic profile of the respondents, various types of code-switching, and factors that influence the use of it. The questionnaire's content validity was examined carefully by content experts and it was considered as valid because a cross-check has been done. The reliability of the questionnaire has also been verified by conducting a pilot test to a group of 10 students from four different faculties. After the students were done with the pilot test, the questions were improvised. Other than that, the items in the questionnaire were adapted from published articles. Reliability has been analysed by utilising Cronbach's Alpha on SPSS 21. The results obtained from the reliability analysis was 0.905 . Therefore, the questionnaire is reliable and can be utilised for this study. The questionnaire was then being disseminated to the subjects in four faculties after measuring the validity and reliability of the questionnaire.

\section{Results}

\subsection{Demographic of the Samples}

Table 1. Demographic Distribution of the Subjects by Faculty and Gender

\begin{tabular}{ccccc}
\hline & Faculty & \multicolumn{2}{c}{ Gender } & \multirow{2}{*}{ Total } \\
\cline { 3 - 4 } & & Male & Female & \\
\hline 1 & Academy of Language Studies & $8(8.9 \%)$ & $27(30.0 \%)$ & $35(38.9 \%)$ \\
2 & Faculty of Law & $10(11.1 \%)$ & $9(10.0 \%)$ & $19(21.1 \%)$ \\
3 & Faculty of Communication and Media Studies & $8(8.9 \%)$ & $6(6.7 \%)$ & $14(15.6 \%)$ \\
4 & Faculty of Education & $12(13.3 \%)$ & $10(11.1 \%)$ & $22(24.4 \%)$ \\
& Total & $38(42.2 \%)$ & $52(57.8 \%)$ & $90(100 \%)$ \\
\hline
\end{tabular}

Table 1 shows demographic distribution of the subjects by faculty and gender. From the total of 90 subjects, 35 (38.9\%) were from Academy of Language Studies, 19 (21.1\%) were from Faculty of Law, 14 (15.6\%) were from Faculty of Communication and Media Studies and 22 (24.4\%) were from Faculty of Education. Subjects consisted of $8(8.9 \%)$ males and 27 (30.0\%) females enrolled in the Academy of Language Studies. Other than that, there were $10(11.1 \%)$ males and $9(10.0 \%)$ females enrolled in Faculty of Law. For Faculty of Communication and Media Studies, there were 14 students who were $8(8.9 \%)$ males and $6(6.7 \%)$ females. Faculty of Education consisted of 12 (13.3\%) males and $10(11.1 \%)$ females.

Table 2. Demographic Distribution of the Subjects by Faculty and Semester

\begin{tabular}{|c|c|c|c|c|c|c|c|c|c|}
\hline \multirow{2}{*}{ Faculty } & \multicolumn{8}{|c|}{ Semester } & \multirow[b]{2}{*}{ Total } \\
\hline & 1 & 2 & 3 & 4 & 5 & 6 & 7 & 8 & \\
\hline $\begin{array}{c}\text { Academy of Language } \\
\text { Studies }\end{array}$ & 0 & 2 & 5 & 3 & 13 & 12 & 0 & 0 & 35 \\
\hline Faculty of Law & 0 & 0 & 0 & 1 & 2 & 15 & 0 & 1 & 19 \\
\hline $\begin{array}{l}\text { Faculty of Communication } \\
\text { and Media Studies }\end{array}$ & 2 & 2 & 0 & 4 & 4 & 2 & 0 & 0 & 14 \\
\hline Faculty of Education & 4 & 1 & 1 & 1 & 0 & 4 & 9 & 2 & 22 \\
\hline Total & $\begin{array}{c}6 \\
(6.7 \%)\end{array}$ & $\begin{array}{c}5 \\
(5.6 \%)\end{array}$ & $\begin{array}{c}6 \\
(6.7 \%)\end{array}$ & $\begin{array}{c}9 \\
(10 \%)\end{array}$ & $\begin{array}{c}19 \\
(21.1 \%)\end{array}$ & $\begin{array}{c}33 \\
(36.7 \%)\end{array}$ & $\begin{array}{c}9 \\
(10 \%)\end{array}$ & $\begin{array}{c}3 \\
(3.3 \%)\end{array}$ & $\begin{array}{c}90 \\
(100 \%)\end{array}$ \\
\hline
\end{tabular}

Table 2 illustrates demographic distribution of the subjects by semester and faculty. 33 (36.7\%) subjects are semester 6 students which consisted of 12 students from Academy of Language Studies, 15 students from 
Faculty of Law, 2 students from Faculty of Communication and Media Studies and 4 students from Faculty of Education. Next, 19 (21.1\%) subjects are semester 5 students who were 13 students enrolled in Academy of Language Studies, 2 students enrolled in Faculty of Law and 4 students enrolled in Faculty of Communication and Media Studies. Other than that, there were $9(10.0 \%)$ subjects who were in semester 4 and 7 respectively. 9 subjects in semester 4 consisted of 3 students from Academy of Language Studies, 4 students from Faculty of Communication and Media Studies and 1 student from Faculty of Law and Faculty of Education respectively. Meanwhile, 9 subjects in semester 7 consisted of students enrolled in Faculty of Education. There were 6 (6.7\%) semester 3 and semester 1 students respectively. 6 subjects in semester 3 consisted of 5 students enrolled in Academy of Language Studies and 1 student enrolled in Faculty of Education. However, 6 subjects in semester 1 consisted of 4 students from Faculty of Education and 2 students from Faculty of Communication and Media Studies. Besides that, $5(5.6 \%)$ subjects in semester 2 were two students from Faculty of Communication and Media Studies and one student from Faculty of Education. Lastly, there were 3 (3.3\%) subjects in semester 8. Two subjects were students enrolled in Faculty of Education and one subject was a student enrolled in Faculty of Law.

\subsection{Research Question 1: What Are the Types of Code-switching Mostly Used by UiTM Undergraduates on} Whatsapp?

Table 3. Undergraduates' Ranking of Types of Code-switching

\begin{tabular}{ccccc}
\hline Ranking & Factors & Mean & Std. Deviation & $\mathrm{N}$ \\
\hline 1 & Inter-sentential Code-switching & 3.6111 & .58912 & 90 \\
2 & Metaphorical Code-switching & 3.5815 & .60287 & 90 \\
3 & Intra-sentential Code-switching & 3.1730 & .43862 & 90 \\
4 & Situational Code-switching & 3.1500 & .54541 & 90 \\
5 & Tag Switching & 2.9540 & .41681 & 90 \\
\hline
\end{tabular}

The first objective of this research is to find out the types of code-switching mostly utilised by UiTM undergraduates on WhatsApp. The result of the descriptive analysis on Section B of the questionnaire explained undergraduates' ranking of 5 types of code-switching. Table 3 illustrates the undergraduates' ranking of types of code-switching. In the table above, the types of code-switching are arranged ascending from the highest mean score to the lowest mean score. As shown in Table 3, inter-sentential code-switching was considered as the most frequent type of code-switching on WhatsApp used by UiTM undergraduates $(\mathrm{M}=3.61$, Std. Deviation $=.589)$ followed by metaphorical code-switching $(M=3.58$, Std. Deviation $=.602)$. Next, the respondents also used intra-sentential code-switching on WhatsApp $(\mathrm{M}=3.17$, Std. Deviation $=.438)$. Other than that, respondents used situational code-switching on WhatsApp $(\mathrm{M}=3.15$, Std. Deviation $=.545)$. The least used type of code-switching by UiTM undergraduates on WhatsApp was tag-switching $(\mathrm{M}=2.95$, Std. Deviation $=.416)$.

The reason why inter-sentential code-switching was the most common type of code-switching on WhatsApp among UiTM undergraduates $(\mathrm{M}=3.61$, Std. Deviation $=.589)$ was mainly due to the fact that people find it is more convenient to communicate with others by using a different language in a sentence then switching to another language in the following sentence. Using inter-sentential code-switching will make other people understand the sentence better. Other than that, the second most common type of code-switching among the undergraduates was metaphorical code-switching $(\mathrm{M}=3.58$, Std. Deviation $=.602)$. According to question item 21, 22 and 23, the respondents preferred to insert metaphorical code-switching when they wanted to strengthen their apology, complaint and request. Besides that, the third most frequent type of code-switching was intra-sentential code-switching $(\mathrm{M}=3.17$, Std. Deviation $=.438)$. Intra-sentential code-switching occurs when the person switches to a different language within a sentence. However, most of the respondents disagreed over the fact that they regularly switch to a different language within a sentence when they send WhatsApp messages to lecturers but they agreed that they regularly code-switch within a sentence when they send WhatsApp messages to family members, friends and classmates.

\subsection{Research Question 2: What Are the Factors That Influence the Undergraduates to Code-switch on WhatsApp?}

The second objective of this research is to investigate factors that influence the use of code-switching among undergraduates while communicating using WhatsApp. The result of the descriptive analysis on Section C of the questionnaire revealed undergraduates' ranking of 7 factors of code-switching. Table 4 represents the undergraduates' ranking of seven factors of code-switching. The factors are ranked ascending from the highest 
mean score to the lowest mean score. According to the table, 'Habitual Expression' was the main factor that influences the undergraduates to code-switch on WhatsApp $(M=3.77$, Std. Deviation $=.468)$, followed by 'Emphasis of a Point' $(\mathrm{M}=3.74$, Std. Deviation $=.509)$. Besides that, 'Lack of Vocabulary' was also the factor that motivates students to switch to another language while texting on WhatsApp ( $M=3.68$, Std. Deviation $=.568)$. Students tend to code-switch a lot on WhatsApp depending on the 'Mood of the Speaker' $(\mathrm{M}=3.53$, Std. Deviation $=.641)$. 'Language Preference' was also one of the reasons that influences students to switch to another language on WhatsApp $(\mathrm{M}=3.46$, Std. Deviation $=.690)$, followed by 'Display of Identity' $(\mathrm{M}=3.22$, Std. Deviation = .549). However, the factor 'Linguistic Background' had the lowest mean score $(M=3.16$, Std. Deviation $=.788$ ) which shows that not many students code-switched according to the linguistic background of the other person during a conversation on WhatsApp.

Table 4. Undergraduates' Ranking of Factors of Code-switching

\begin{tabular}{ccccc}
\hline Ranking & Factors & Mean & Std. Deviation & $\mathrm{N}$ \\
\hline 1 & Habitual Expression & 3.7778 & .46875 & 90 \\
2 & Emphasis of Point & 3.7444 & .50971 & 90 \\
3 & Lack of Vocabulary & 3.6806 & .56839 & 90 \\
4 & Mood of Speaker & 3.5370 & .64127 & 90 \\
5 & Language Preference & 3.4667 & .69022 & 90 \\
6 & Display of Identity & 3.2222 & .54966 & 90 \\
7 & Linguistic background & 3.1667 & .78889 & 90 \\
\hline
\end{tabular}

Based on the results above, it can be observed that 'Habitual Expression' was the most chosen factor that influences UiTM undergraduates to code-switch while communicating using WhatsApp $(\mathrm{M}=3.77$, Std. Deviation $=.468$ ). This is because respondents preferred to insert discourse particles such as "you know", "lah" and "kan" while texting. Other than that, most of the respondents also chose 'Emphasis of a Point' $(\mathrm{M}=3.74$, Std. Deviation $=.509$ ) as the factor that influences them to code-switch on WhatsApp. This is because the respondents assumed that switching to another language during an argument can add more force to the statement. A lot of respondents chose 'Lack of Vocabulary' $(\mathrm{M}=3.68$, Std. Deviation $=.568)$ as the factor because they preferred to code-switch when they are unable to explain using their first language or second language, and they also code-switch when they can't find equivalent words in their first language. Other than that, the respondents often switch to another language when texting on WhatsApp to overcome issues such as grammatical problems.

\section{Discussion}

Based on the results received from the questionnaire of this study, the undergraduates preferred to use inter-sentential code-switching by switching from Malay language to English language from one sentence to another sentence on WhatsApp so that it can be easily understood by the reader. Inter-sentential code-switching helps WhatsApp's users to achieve an effective communication with one another. Another type of code-switching that the undergraduates regularly used was metaphorical code-switching. The undergraduates frequently use metaphorical code-switching when they want to strengthen their apology to others. They also prefer switching to another language when they want to strengthen their complaint or request for favours. This is because metaphorical code-switching allows the speakers to modify the tone of the conversation. The results yielded show that the main factor for undergraduates to code-switch on WhatsApp was due to 'Habitual Expression'. This is because it has become a habit of them to code-switch by using discourse particles, namely "you know", "i mean" "lah" or "kan". This is rather typical for a multiligual country like Malaysia (David, 2003; Alinda, 2019). Malaysians have a higher tendency to use the discourse particles while texting in a full-English sentence as Malaysia is a multiracial country and various languages are being used by different races. Therefore, Bahasa Rojak or Salad Language has become a norm in Malaysia. Other than that, the second factor that most of the respondents agreed to was 'Emphasis of a Point'. All undergraduates from Academy of Language Studies, Faculty of Communication and Media Studies and Faculty of Education preferred to code-switch to strengthen a statement when arguing on WhatsApp. However, not all undergraduates from Faculty of Law agreed with it. This indicates that Faculty of Law's undergraduates preferred to speak in full English or Bahasa Melayu sentence during an argument on WhatsApp. This result is in line with studies conducted by Nik \& Suthagar (2013) and Almelhi (2020) that people switch and shift to a different language in a conversation to make the utterance more understandable for others and simultaneously to strengthen the point in an argument to invariably show solidarity. The majority of respondents from the four faculties also agreed that 
'Lack of Vocabulary' was one of the factors that triggered them to code-switch. The respondents mostly responded "Agree" and "Strongly Agree" that they code-switch when they are unable to explain using their first or second language and when they can't find equivalent words in their first language. This shows that the undergraduates chose to explain in any language that they could think of when texting on WhatsApp as WhatsApp is a type of synchronous CMC where it requires instant response and both user and receiver should be logged in simultaneously.

\section{Conclusion}

The study was primed to investigate an asynchronous computer-mediated communication (CMC) between bilingual university students in Malaysia, in particular via Whatsapp by arrogating a functional approach in analyzing the diverse types and influences for codeswitching (CS). The findings revealed that the respondents from four faculties (Academy of Language Studies, Faculty of Law, Faculty of Communication and Media Studies and Faculty of Education) regularly code-switch with one another on WhatsApp. The most used form of code-switching by the respondents was inter-sentential code-switching as they want the message to be understood easily by readers. The main factor that influenced the respondents to code-switch is 'Habitual Expression', denoting customary decorum and completely nothing out of the ordinary, especially in the Malaysian context. The 'Habitual Expressions' such as discourse particles such as 'lah' and 'kan' are inserted to better convey the messages. It is noteworthy to mention that these diplays of behaviours are done unconsciously, reflecting the speakers' interaction patterns. At this juncture, the findings are replete with illustrations, attributed to the multi-ethnic identities and environment in Malaysia. Other factors of code-switching such as 'Emphasis of a Point' and 'Lack of Vocabulary', which also instigated the students to habitually switch to another language when communicating using WhatsApp. Ultimately, this study confirms that linguistic means are associated and shaped by the speakers' expressions of identity, albeit via mediated communication. Likewise, the findings of the study are akin to the existing pool of researches on the use of first and second languages within a multilingual context. Future researches on CS and CMC in other multilingual settings can be done to warrant better understanding of the relationship between the two, and to remit its teaching, learning and communicative potential, especially in the language teaching and learning so as to second language learners (LL2) are able to foster academically successful attitudes and cultures from a standardized language model.

\section{References}

Alinda, A. R. (2019). The types and functions of code-switching among Malay bilinguals/Alinda Abdul Rashid (Doctoral dissertation, University of Malaya).

Almelhi, A. M. (2020). Understanding code-switching from a sociolinguistic perspective: A meta-analysis. International Journal of Language and Linguistics, 8(1), 34-45. https://doi.org/10.11648/j.ij11.20200801.15

Ariffin, K., \& Husin, M. S. (2011). Code-switching and code-mixing of English and Bahasa Malaysia in content-based classrooms: Frequency and attitudes. Linguistic Journal, 5, 220-247.

Auer, P. (2020). The pragmatics of code-switching: A sequential approach. In The bilingualism reader (pp. 123-138). Routledge. https://doi.org/10.4324/9781003060406-14

Barhoumi, C. (2015). The effectiveness of WhatsApp mobile learning activity theory on students' knowledge management. J. of Contemporary Educational Tech., 6(3), 221-238. https://doi.org/10.30935/cedtech/6151

Blom, J. P., \& Gumperz, J. J. (2000). Social meaning in linguistic structure: Code-switching in Norway. The bilingualism reader, 111-136.

Che, S. M., Che, H. C. S., Hassan, A. B., \& Bahtiar, M. (2018). Understanding the usage of WhatsApp among Malaysian employees through the lens of social influence theory. International Journal of Engineering \& Technology, 7(4.38), 1039-1043. https://doi.org/10.14419/ijet.v7i4.38.27635

Choy, W. F. (2011). Functions and reasons for code-switching on Facebook by UTAR English-Mandarin Chinese bilingual undergraduates. Retrieved from http://eprints.utar.edu.my/263/1/EL-2011-0803813-1.pdf

Constine, J. (2018). WhatsApp hits 1.5 billion monthly users. \$19B? Not so bad. Retrieved from https://techcrunch.com/2018/01/31/whatsapp-hits-1-5-billion-monthly-users-19b-not-so-bad/

David, M. K. (2003). The Pakistani community in Machang, Kelantan: Reason for language shift. International Journal of the Sociology of Language, 161(1), 47e53. https://doi.org/10.1515/ijsl.2003.028

Dewaele, J. M., \& Wei, L. (2014). Attitudes towards code-switching among adult mono-and multilingual language users. Journal of Multilingual and Multicultural Development, 35(3), 235-251. https://doi.org/10.1080/01434632.2013.859687 
Fricke, M., Kroll, J. F., \& Dussias, P. E. (2016). Phonetic variation in bilingual speech: A lens for studying the production-comprehension link. J of Mem. \& L., 89, 110-137. https://dx.doi.org/10.1016/j.jml.2015.10.001

Gaudart, H. (2002). English language teaching practices. Petaling Jaya: Sasbadi Sdn. Bhd.

Gumperz, J. J. (1982). Discourse strategies. Cambridge: C. U. P. https://doi.org/10.1017/CBO9780511611834

Hassan, N., \& Hashim, A. (2009). Electronic English in Malaysia: Features and language in use. English Today, 25(4), 39-46. https://doi.org/10.1017/S0266078409990435

Halim, H. A., Nadri, H. N. A., \& Mahmood, F. (2015). Code mixing on Facebook among Malaysian TESL students. Advances in Social Sciences Research Journal, 2(5). 27-33. https://doi.org/10.14738/assrj.25.1146

Heller, M., \& Pfaff, C. W. (2008). Code-switching. In Kontaktlinguistik (pp. 594-609). De Gruyter Mouton. https://doi.org/10.1515/9783110132649.1.6.594

Hoffmann, C. (2014). An introduction to bilingualism. NY: Routledge. https://doi.org/10.4324/9781315842035

Holmes J. (1992). Code-switching or code-mixing. Language choice in multilingual communities. An Introduction to Sociolinguistics (pp. 41-52). United Kingdom, UK. Longman Group UK Limited 1992.

Ismail, O., Mohd Roslan, A. D., \& Mahmud, M. M. (2021). The occurrence of code-switching among Malaysian undergraduates on WhatsApp: Review of the literature. European Journal of English Language Teaching, 6(5), 23-38. https://doi.org/10.46827/ejel.v6i5.3848

Joanna, T. S. (2014). Code switching in the Malaysian ESL classroom (Thesis, Master of Arts). Univ. of Otago.

John, D. A. F., \& Dumanig, F. P. (2013). Identity construction and code switching in English newspaper advertisements. The J.of the South East Asia Research Centre for Comm.\& Humanities, 5(1), 57-71.

Lee, H. L. J. (2010). Code switching in the Teaching of English as a second language to secondary school students. Malaysian Journal of ELT Research, 6, 1-45.

Malik, L. (1994). Socio-linguistics: A study of code-switching. New Delhi, ND: Anmol Publications Pvt. Ltd.

McLellan, J. (2012). The view from below: Code-switching and the influence of substrate languages in the development of Southeast Asian Englishes. In E.-L. Low \& A. Hashim (Eds.), English in Southeast Asia: Features, Policy and Language in Use (pp. 267-288). https://doi.org/10.1075/veaw.g42.21mcl

Newman, N., Fletcher, R., Kalogeropoulos, A., David A. L. L., \& Nielsen, R. K. (2017). Reuters Institute Digital News Report 2017 (pp. 116-122). Oxford University.

Nik, M. N. I. A., \& Suthagar, N. (2013). The role of code-switching as a communicative tool in an ESL teacher education classroom. Procedia - Social and Behavioral Sciences, (90), 458-467 https://doi.org/10.1016/j.sbspro.2013.07.115

Nil, Zurina, M., \& Shamala, P. (2012). Code-switching in Gol \& Gincu. Procedia - Social and Behavioral Sciences, (66), 169-175. https://doi.org/10.1016/j.sbspro.2012.11.258

Noor, A. Q., \& Mostafa, A. E. (2017). Code-switching usage in social media: A case study from Oman. International Journal of Information Technology and Language Studies, 1(1), 25-38.

Paramasivam, M. (2010). Codeswitching in communication: A sociolinguistic study of Malaysian secondary school students. Pertanika J. Soc. Sci. \& Hum., 18(2), 407 -415.

Poplack, S. (1980). Sometimes I'll start a sentence in Spanish y termino en espanol: Toward a typology of code-switching. In L. Wei (Ed.), The Bilingualism Reader (pp. 213-243). London and New York: Routledge. https://doi.org/10.4324/9781003060406-24

Puteh, M., Bakar, S. A., Mohamad, A. R., Ramly, L. Z., Sazalli, N. A. H., Zainon, O., ... Bannister, N. (2020). Online Collaborative Learning via Astronomy Online Lab: A Cross-cultural Communicative Experience for Malaysian and UK Students. Universal Journal of Educational Research, 8(11C), 45-54. https://doi.org/10.13189/ujer.2020.082306

Rasdi, N. I. B. (2016). Intrasentential code-switching among Malays in Malaysia on Facebook (Doctoral dissertation, University of Essex).

Resende, G., Melo, P., Sousa, H., Messias, J., Vasconcelos, M., Almeida, J., \& Benevenuto, F. (2019, May). (Mis) information dissemination in WhatsApp: Gathering, analyzing and countermeasures. In The World Wide Web Conference (pp. 818-828). https://doi.org/10.1145/3308558.3313688

Schendl, H., \& Wright, L. (Eds.). (2011). Code-switching in early English. Berlin: De Gruyter Mouton. 
https://doi.org/10.1515/9783110253368

Shen, A., Gahl, S., \& Johnson, K. (2020). Didn't hear that coming: Effects of withholding phonetic cues to code-switching. Bilingualism: Language and Cognition, 23(5), 1020-1031. https://doi.org/10.1017/S1366728919000877

Suryawati, N. (2013). An Analysis of Code switching Occurred in A Puppet Show. D J Anglicist, 2(1), 41-51.

Tamargo, R. E. G., Kroff, J. R. V., \& Dussias, P. E. (2016). Examining the relationship between comprehension and production processes in code-switched language. Journal of Memory and Language, 89, 138-161. https://doi.org/10.1016/j.jml.2015.12.002

Trudgill, P. (2000). Sociolinguistics. London: Penguin.

\section{Copyrights}

Copyright for this article is retained by the author(s), with first publication rights granted to the journal.

This is an open-access article distributed under the terms and conditions of the Creative Commons Attribution license (http://creativecommons.org/licenses/by/4.0/). 